\title{
Income and Body Mass Index in Europe*
}

\author{
Jaume Garcia Villar \\ Universitat Pompeu Fabra
}

\author{
Climent Quintana-Domeque \\ Princeton University
}

This draft: December 2006

\begin{abstract}
Obesity is alarming public health authorities around the world. Given this situation it is important to study its determinants. This paper focuses on the economic determinants of obesity. More specifically, we explore the empirical relationship between lifetime income and body mass index (BMI) in seven European Union countries in the short run. To study such a relationship, we make use of an accounting identity that relates current BMI to last year's BMI and current levels of both food consumption and physical activity. We estimate a reduced-form version of such an identity which relates current BMI to last year's BMI and lifetime income. Theoretically, lifetime income should affect contemporaneous BMI through its effect on both current consumption of food and current physical activity. Our results indicate that, once last year BMI's is taken into account, the relationship between lifetime income and BMI is at most weak. Such a finding suggests that income-based public policies are not likely to be effective in the fight against obesity in the short run.
\end{abstract}

JEL Classification: I12, I18.

Key Words: Europe, obesity, permanent income, short run.

${ }^{*}$ This work is motivated by authors' previous research on obesity and labor market outcomes in Europe, "Obesidad y Mercado Laboral en la Unión Europea: una primera aproximación", included in the ISOS Project, June 2003, European Union Contract Number: VS/2001/0497. Garcia acknowledges financial support from BEC2002-04294 and SEJ2005-08783-C04-01, and Quintana-Domeque from Banco de España. Of course, all remaining errors are ours. Corresponding author: Industrial Relations Section, Princeton University, Princeton, NJ 08544, USA. E-mail: climent@princeton.edu. 


\section{Introduction}

Obesity poses one of the greatest public health challenges for the 21st century, with particularly alarming trends in several parts of the world, including the World Health Organization (WHO) European region (WHO, 2005). ${ }^{1}$ According to the WHO (2003), obesity prevalence has increased by 10-40\% in most European countries over the last decade. Furthermore, obesity among children is growing fast, especially in Southern Europe, with rates from $20 \%$ to more than 35\% (International Obesity Task Force, 2002, 2003, 2005).

As highlighted by Philipson (2001), obesity is not only a health risk factor, but it is also a major health economics and public finance issue, which accounts for 2 and $3.5 \%$ of the overall health care budgets in France and Portugal, respectively (Thompson and Wolf, 2001). However, given the current fast-growing trends in obesity, and that these estimates are outdated, these are considered lower bounds for the actual costs. In Spain, for example, nearly $7 \%$ of health care costs are associated with obesity (WHO, 2005). Hence, it is a priority to understand the determinants of body mass index (BMI), and those of overweight and obesity, in particular. In this article, we perform an empirical analysis on the economic factors behind obesity in Europe. More specifically, we study the role of income as a BMI determinant.

The link between income and BMI emerges because the former can be seen as a determinant of the later through its effect on both consumption of food and physical activity, which are the main explanatory factors of BMI. BMI is mainly determined by both caloric intakes (consumption of food) and expenditure of calories (physical activity). According to standard economic theory, individuals decide the amounts of food consumption and physical activity depending on their permanent or lifetime income. Moreover, current BMI can be seen as a function of last year's BMI and current levels of food consumption and physical activity. Hence, there is a reduced-form relationship between BMI and lifetime income.

The purpose of this paper is to estimate a reduced-form relationship between BMI and lifetime income conditional on last year's BMI. The decision to focus on such a conditional

\footnotetext{
${ }^{1}$ Overweight and obesity are usually defined by means of the Body Mass Index (BMI), which is defined as the individual's body weight (in kilograms) divided by the square of the height (in square meters). According to the WHO, overweight is defined as $25 \leqslant$ BMI $<30$, and obesity is defined as BMI $\geqslant 30$.
} 
relation relies on two key grounds. First, we are interested in having some idea about the role and the magnitude of the effect of public policies such as income transfers on BMI determination in the short run. Conditioning this association on last year's BMI, we are estimating the direct association between permanent income and current BMI without capturing the cumulative effect of permanent income on current BMI through its effect on last year's BMI. Without conditioning on last year's BMI, we would be trying to estimate the total association between current BMI and permanent income, i.e., the effect of permanent income on current BMI through all its effects on the past BMIs. Second, given the dynamics in BMI determination, in order to reliably estimate such an effect, we should control for BMI at birth. Without such a control, our estimated total association is likely to be seriously biased. Hence, unless we are willing to make heroic assumptions, the bias when estimating the total association between lifetime income and BMI is likely to be much larger than when estimating the short term association.

The structure of the paper is as follows. Section 2 presents a brief literature review and highlights the contributions of our work. Section 3 describes why we should expect to find a relationship between lifetime income and current BMI and the empirical specification to be estimated. Section 4 contains the description of the dataset and the variables used in the empirical analysis. Section 5 presents the results. Finally, section 6 concludes and suggests further avenues for future research.

\section{A Brief Literature Review}

Previous economic analysis of obesity has crystallized in both empirical and theoretical research. Perhaps the most well known papers in this field are those by Philipson and Posner (1999), Lakdawalla and Philipson (2002), Cutler et al. (2003) and Chou et al. (2004). There is also a recent paper by Lakdawalla and Philipson (2006) where they look at the effect of job-related exercise on BMI determination. Although it is not our aim to offer a description of this literature (see Finkelstein et al., 2005), for the purposes of our study, an empirical analysis using individual European data, we focus our review on the works by Michaud and 
van Soest (2005) and Sanz-de-Galdeano (2005).

Sanz-de-Galdeano (2005) provides an interesting descriptive analysis of the European obesity epidemic with comparable country results. She uses the data from the European Community Household Panel (ECHP), like the present study, avoiding one of the points emphasized by Sobal and Stunkard (1989), which is that differences in the methodology, the measure of socioeconomic status, or the data collection procedure in each country-specific study can lead to misleading conclusions. Her results show that household income is negatively related to the probability of being obese for women, but for men her results are mixed. Nevertheless, her approach is more concerned about the socioeconomic correlates of obesity (current income, employment status, educational level, etc.) than about the economics behind it. Put it differently, the economic mechanism behind the obesity-income relationship is not well-defined since her analysis is really focused on the role of socioeconomic status on obesity. This is problematic if one is really interested in the effect of a particular variable. Without any kind of structure behind the empirical specification, adding several SES indicators are likely to obfuscate the factors we are really interested in due to overcontroling. Moreover, since she focuses on obesity, which is defined using BMI derived from self-reported data on height and weight, her analysis is likely to suffer from shortcomings due to obesity misclassification (see Appendix A).

Michaud and van Soest (2005), in their very preliminary and incomplete work, explore the EU-US differences in obesity for people older than 50 using data from both the Health and Retirement Study (HRS), for the US, and the Survey of Health, Ageing and Retirement in Europe (SHARE), for European countries. Both surveys contain information on physical activity and food consumption, allowing them to estimate a well-defined BMI equation as a function of caloric intakes and caloric outtakes (Cutler et al., 2003). This makes more transparent the economic relationship between income and BMI. Nevertheless, they cannot estimate the BMI's laws of motion, an equation defining current BMI as a function of last year's BMI and current levels of physical activity and food consumption. The cross-sectional character of their dataset forces them to estimate a steady-state equation for the BMI, which 
might compromise their estimates given the well documented inverted-U relationship between BMI and age. Their results show that current income is hardly related to BMI, conditional on employment status and wealth.

In this paper, we depart from the existing literature in three different ways. First, rather than just focusing on obesity and current income, we look at the relationship between lifetime income and current BMI. The decision to study lifetime rather than current income is because it is the former and not the later which determines both food consumption and physical activity. Second, the model proposed by Michaud and van Soest (2005) is intrinsically dynamic, but the cross-sectional character of their dataset forces them to assume BMI is in its steady state, which is quite questionable since this means that the depreciation rate of the individual is constant over age. Although we do not have data on consumption or physical activity, the longitudinal character of the ECHP makes possible to estimate a reduced-form version of the BMI's law of motion, where current BMI depends on both last year's BMI and permanent income. Finally, while the samples in Sanz de Galdeano (2005) and Michaud and van Soest (2005) correspond to people aged above 18 and above 50, respectively, we restrict our attention to young people, between 25 and 54 in 2001. This helps us to deal with measurement error issues since the difference between self-reported and objectively measured anthropometric indicators is likely to be more or less constant for people between 20 and 60, at least taking into account the available evidence for the US (Thomas and Frankenberg, 2002).

Overall, we aim to answer a well-defined empirical question, namely, whether permanent income is likely to have a significant effect on current BMI in the short run. Our purpose is not to provide a causal estimate of the permanent income effect on BMI, since disentangling causality from correlation without any kind of exogenous variation in permanent income is a challenging task. Nevertheless, for public policy purposes, it is important to determine the extent to which lifetime income and current BMI are related in the short run. Such a descriptive analysis is a necessary step prior to any causal analysis. 


\section{An Accounting Identity relating BMI to Income}

This section, based on Michaud and van Soest (2005), is intended to explain why income is likely to be a determinant of BMI.

We can start by saying that BMI is mainly determined by both intake and expenditure of calories. Basically, caloric intake is obtained via food consumption, while physical activity is the responsible for the expenditure of calories. In the following discussion we are going to use the terms caloric intake (expenditure of calories) and food consumption (physical activity) interchangeably. We assume that the BMI of individual $i$ at age $t$ evolves according to

$$
B M I_{i, t}=(1-\delta) B M I_{i, t-1}+\beta C_{i, t}+\gamma P_{i, t}+\epsilon_{i, t}
$$

where $C_{i, t}$ is some measure of food consumption and $P_{i, t}$ is some measure of physical activity, hence $\beta>0$ and $\gamma<0$, although we should note that in the case of athletes, if the reduction in fat is higher than the increase in muscle, BMI will increase with physical activity (on the accuratness of BMI and other indicators as measures of fatness, see Burkhauser and Cawley, 2006). The coefficient $\delta$ is the depreciation rate of BMI, which can be thought of as the Basal Metabolic Rate (or Resting Metabolic Rate), which is the number of calories we need to burn in order to fuel essential bodily processes and keep our organs and tissues in working order. The error term $\epsilon_{i, t}$ captures anything else affecting BMI. Obviously the estimation of such a specification is merely an accounting exercise and its behavioral contain to perform policy recommendations is limited.

Although Michaud and van Soest (2005) propose such a specification, they cannot estimate it due to the cross-sectional character of their dataset. They try to overcome such a shorthcoming by arguing that for people 50 and above it can be assumed that BMI is in its steady state $\left(B M I_{i, t}=B M I_{i, t-1}\right)$. Hence, provided that $(1-\delta)<1$, they can estimate

$$
B M I_{i}=\beta^{*} C_{i}+\gamma^{*} P_{i}+\epsilon_{i}^{*}
$$

where the superscript ${ }^{*}$ designates the corresponding coefficient in (1) divided by $\delta$. They 
estimate the specification (2) for each region $j$ (US and Europe) and for men and women separately as follows

$$
B M I_{i, j}=\beta_{j}^{*} C_{i, j}+\gamma_{j}^{*} P_{i, j}+\epsilon_{i, j}^{*}
$$

The longitudinal character of the ECHP allows us to estimate a reduced-form version of equation (1). However, since the ECHP does not provide any kind of information on food consumption or physical activity, we can estimate at most a reduced-form version of (1). Thinking of an economic framework where individuals maximize their utility subject to an inter-temporal budget constraint and equation (1), it is easy to see that both the demand for calories and the demand for physical activity depend on real lifetime income. For illustrative purposes we assume that the individual demands for food consumption and physical activity can be linearly approximated by

$$
\begin{aligned}
& C_{i, t}=\rho_{1} m_{i, \tau}+\nu_{1 i, t} \\
& P_{i, t}=\rho_{2} m_{i, \tau}+\nu_{2 i, t}
\end{aligned}
$$

where $m_{i, \tau}=\sum_{t=0}^{\tau} m_{i, t}$ is defined as the real permanent income (or real lifetime income), $\nu_{1 i, t}$ and $\nu_{2 i, t}$ are error terms, and $\tau$ is the number of periods of life. These equations reflect the fact that current levels of consumption and physical activity depend on permanent income, $m_{i, \tau}$. Unfortunately, our dataset does not contain information during the entire life of any individual. Nevertheless, an average income indicator over the entire span of the ECHP panel (1994-2001) can be thought as a proxy for permanent income.

To obtain the most reliable estimator of permanent income, we consider only non-attritors, individuals that have taken part into the survey each year since 1994. Although the high level of attrition in the ECHP can be translated into both imprecise and biased estimates, evidence provided in Behr et al. (2005) suggests that neither the analysis of income nor the ranking of national results are disturbed. Furthermore, Jones et al. (2006) find that health-related 
attrition in the ECHP does not affect the estimates of the associations between health and socioeconomic status, which are robust with or without adjusting for health-related attrition. Since BMI can be considered one of the dimensions of health status and because it is also a stock variable, we consider fair to assume that the associations between BMI and income are robust with or without adjusting for attrition.

Plugging (4) and (5) into (1), we have the following reduced-form

$$
B M I_{i, t}=(1-\delta) B M I_{i, t-1}+\theta m_{i, \tau}+u_{i, t}
$$

where $\theta=\beta \rho_{1}+\gamma \rho_{2}$ and $u_{i, t}=\epsilon_{i, t}+\beta \nu_{1 i, t}+\gamma \nu_{2 i, t}$.

Provided that the unobservables captured by $u_{i, t}$ are not sistematically related to both permanent income and BMI, we have

$$
\left.\frac{\partial B M I_{i, t}}{\partial m_{i, \tau}}\right|_{d B M I_{i, t-1=0}}=\theta
$$

The coefficient $\theta$ captures the direct effect of permanent income on current BMI without capturing its effect on last year's BMI, i.e., it is the short-run effect of permanent income on BMI.

Moreover, applying recursive substitution to (6) in order to obtain a specification for current $\mathrm{BMI}$ in terms of BMI two years ago, $B M I_{i, t-2}$, we get

$$
B M I_{i, t}=(1-\delta)^{2} B M I_{i, t-2}+(2-\delta) \theta m_{i, \tau}+\left(u_{i, t}+(1-\delta) u_{i, t-1}\right)
$$

In such a case

$$
\left.\frac{\partial B M I_{i, t}}{\partial m_{i, \tau}}\right|_{d B M I_{i, t-2=0}}=(2-\delta) \theta
$$

Finally, applying recursive substitution to (6) until having an expression in terms of BMI at birth, $B M I_{i, 0}$, we get 


$$
B M I_{i, t}=(1-\delta)^{t} B M I_{i, 0}+\frac{1-(1-\delta)^{t}}{\delta} \theta m_{i, \tau}+\sum_{k=0}^{t-1}(1-\delta)^{k} u_{i, t-k}
$$

In this last case we obtain

$$
\left.\frac{\partial B M I_{i, t}}{\partial m_{i, \tau}}\right|_{d B M I_{i, 0=0}}=\frac{1-(1-\delta)^{t}}{\delta} \theta
$$

Under this framework, recursive substitution seems to be appealing. Nevertheless, three points need to be emphasized. First, once we substitute recursively, the error term becomes a finite sume of error terms. As a consequence of this, the potential correlation between omitted relevant factors and permanent income increases. This correlation is maximized when the sum of errors is for the entire period, i.e., from the date of birth until the current date. Second, and related to this last remark, if we were really interested in the total effect of permanent income on current BMI, we would need to estimate this association separately for different age groups, since the coefficients in (10) are age-dependent. Finally, our dataset does not contain data on BMI at birth. For all this, and given that we do not have an available credible source of exogenous variation in permanent income, we believe it is much more sensible to obtain an estimate of the short-run or direct effect of permanent income on BMI. Thus, we avoid to estimate an empirical specification based on recursive substitution.

Finally, since $\beta>0$ and $\gamma<0$, the non-monotonic relationship between BMI and income previously found in the empirical literature (e.g., Lakdawalla and Philipson, 2002) is likely to emerge due to the nonlinearities in (4) and/or (5). It would be interesting to estimate the associations between lifetime income, intake of calories, and caloric expenditure for our dataset, but this does not contain such information. The suspected nonlinearities can be easily accommodated using a set of income percentile dummies. Thus we decide to estimate the following specification

$$
B M I_{i, t}=(1-\delta) B M I_{i, t-1}+\sum_{q} \theta_{q} m_{q i, \tau}+u_{i, t}
$$

where $\theta_{q}=\beta \rho_{1 q}+\gamma \rho_{2 q}$ and $m_{q i, \tau}=1$ if $m_{i, \tau}$ belongs to the $q$ th-percentile, and 0 otherwise. 
Roughly speaking, the $\theta_{q}$ 's are capturing the relationship between current BMI and lifetime income in the short run, since the long term effect is captured by the association between current BMI and last year's BMI.

With this conceptual framework in mind, and after partially accommodating the suspected non-linearity in the BMI-income relationship, we can proceed to the empirical analysis.

\section{Description of the Dataset}

The data used in this paper come from the European Community Household Panel (ECHP), Eurostat, a survey based on a standardized questionnaire that involves annual interviewing of a representative panel of households and individuals in Member States of the European Union during the period 1994-2001. The ECHP covers a wide range of topics on living conditions, and its standardized methodology and procedures yield comparable information across countries. More detailed information on the ECHP is provided by Peracchi (2002) and The Europanel Users Network (http://epunet.essex.ac.uk).

We only use the data for 7 countries available in the ECHP, the ones satisfying the following three requirements: (1) a full ECHP data format (all except Sweden); (2) anthropometric data were collected (all except France, Germany, Luxembourg, Netherlands and United Kingdom); (3) available data over the entire 8-year span (1994-2001) of the ECHP (all the remaining countries except Austria and Finland). Hence, after such a selection, our analysis is focused on Belgium, Denmark, Greece, Ireland, Italy, Portugal, and Spain.

The main dependent variable of the present analysis is current BMI, which is constructed using self-reported height and weight measures. As we discussed previously, self-reported BMI is likely to be reported with error. If we are willing to assume that the measurement error in BMI for young people (25-54) is more or less constant across ages in Europe, like it appears to be the case comparing self-reported and objectively measured weight and height measures for the US (Thomas and Frankenberg, 2002), the loss of precision in our estimates caused by the measurement error is somewhat corrected for by focusing on young people. Nevertheless, since this constant error does not need to be the same across countries, country fixed effects 
are included to capture such heterogeneity.

The two relevant explanatory variables of the present analysis are last year's BMI and lifetime income. We adopt the strategy of including income tercile dummies. This is done for four main reasons. First, this is a flexible and easy way to deal with a non-monotonic relationship between BMI and income. Second, since income is measured with error, a polynomial specification would exacerbate the consequences of measurement error (Griliches and Ringstad, 1970), which could be even worse than the misclassification error consequences associated with the income dummies approach. Third, the income dummies approach is likely to be less sensitive to both influential observations and outliers than the polynomial one. Finally, we heuristically decide to choose terciles rather than quartiles, quintiles, or deciles, because the misclassification error is likely to be higher the larger the number of partitions in the income distribution. This allows us to balance the trade-off between the misclassification costs and the benefits from functional flexibility.

The income tercile dummies used in our analysis are constructed using the total net annual household income excluding individual income from work. This is done to partially deal with the reverse causality bias due to the potential effect of obesity on labor market outcomes (for a US analysis, see Cawley, 2000; for a European analysis, see Garcia and Quintana-Domeque, 2006). ${ }^{2}$ Once individual income from work is subtracted from the total net household income, we adjust the resulting income indicator dividing by both the household size (in fact, the number of adult equivalents, which is defined as $1+0.7^{*}[$ (number of individuals 14 and above $)-1]+0.5^{*}[($ household size $)$ - number of individuals 14 and above $\left.)\right]$ ) and the annual consumer price index for all items (OECD, 2006). This is done to obtain an annual measure of available real income per household member. After computing this annual income measure, its average over the entire ECHP span (8 years) is calculated to obtain a proxy indicator for real lifetime (permanent) income.

As we pointed out before, to obtain the most reliable permanent income estimator, only individuals appearing each wave of the panel are considered in our analysis. Nevertheless,

\footnotetext{
${ }^{2}$ For the sake of comparison, we also performed our analysis without excluding individual income from work. Our main findings are robust to including or not individual income from work. These estimates are available from the authors upon request.
} 
this does not seem to be of critical relevance in terms of non-random attrition implications according to previous empirical evidence on health-related attrition in the ECHP by Jones et al. (2006).

Turning now to the empirical specifications, we perform two kinds of regressions: naïve and augmented. In the naïve specification, current BMI is explained by terciles of lifetime total household income (proxied by the average of income over the entire span of the panel) and last year's BMI. In the augmented specification, current BMI is explained by these variables, but moreover individual heterogeneity is somewhat accounted for using demographic covariates: age, education, marital status, smoking behavior, and number of children (see Appendix $\mathrm{B}$ for a description). Notice that both age and marital status also adjust our permanent income indicator for the fact that demographic factors (household structure) are likely to be permanent income determinants. We also include country fixed effects, which allows us to capture constant differences across countries related to both BMI and income, such as country-specific measurement error in BMI. Notice that the inclusion of country fixed effects implies that the relationship between BMI and income is identified only through withincountry variation.

We estimate different models for each country, allowing for a purely flexible econometric specification, in the sense that none of the coefficients are restricted to be the same across countries. Moreover, the models are estimated for men and women separately. ECHP personal weights are used in all estimations described in this paper. The standard error for each reported coefficient is robust to adjustments for heteroskedasticity.

\section{$5 \quad$ Results}

The sample for each country is restricted to people between 25 and 54 years old in 2001 . Table -1 provides a description of the BMI distribution in each country for men and women separately. The sample sizes are larger for Southern (Greece, Italy, Portugal, Spain) than Northern (Belgium, Denmark and Ireland) countries (see Peracchi, 2002). The average (median) BMI for men ranges from 24.79 (24.38) in Italy to 25.78 (25.47) in Greece, while for 
women it ranges from 22.77 (22.06) in Italy to 24.37 (23.44) in Portugal. According to the estimates of the $90 \%$ percentile for the BMI distribution, Italy seems to be the country with the lowest obesity prevalence, both for men and women. The highest obesity prevalences for male (female) are located in Denmark and Spain (Denmark and Portugal).

\section{[Insert Table -1 about here]}

In tables 2 and 3 we report the OLS estimates for the determinants of BMI according to equation (12) for men and women, respectively. To avoid our OLS estimates being driven by outliers or influential observations in BMI, the samples of each table $(\mathrm{N}=10,004(10,725)$ for men (women)) only include people with a BMI between 15 and 45 in 2000 and 2001. According to these results, there is no statistically significant relationship between BMI and lifetime household income conditional on last year BMI: none of the income coefficients appear to be statistically significant, neither for men (Table -2$)$ nor for women (Table -3$)$.

$$
\begin{aligned}
& \text { [Insert Table }-2 \text { about here] } \\
& \text { [Insert Table }-3 \text { about here] }
\end{aligned}
$$

As tables $4(\mathrm{~N}=9,985)$ and $5(\mathrm{~N}=10,695)$ illustrate, this conclusion is not affected once we control to some extent for individual heterogeneity adding the following covariates: age, education, marital status, current smoking behavior, the number of children between 13 and 15 , and the number of children below 12 .

\section{[Insert Table -4 about here] [Insert Table -5 about here]}

It is worth noting that the results from simply using the log of lifetime income instead of a set of income percentiles dummies do not modify our conclusions. These results are available from the authors upon request.

To understand our empirical findings, it is important to note that we are estimating the associations between current BMI and lifetime income conditional on last year's BMI. Since permanent income is also associated with last year's BMI, the estimated associations are 
capturing the relationship between current BMI and lifetime income in the short run, which appears to be small. Hence, this piece of evidence would seem to support the hypothesis that permanent income is not likely to have sizeable effects on current BMI in the short run.

\section{Discussion}

This paper has presented new empirical evidence about the BMI-income relationship in Europe using the ECHP. Under the influence of works by Michaud and van Soest (2005) and Sanzde-Galdeano (2005) focused on obesity in Europe, we overcame some of their potential pitfalls related to both measurement error and empirical specification issues.

According to our results, there is no statistically significant relationship between BMI and lifetime household income conditional on last year's BMI: none of the income coefficients appear to be statistically significant. Roughly speaking, since permanent income is also associated with last year's BMI, the estimated associations are capturing the relationship between current BMI and lifetime income in the short run, which seems to be small. This piece of evidence would seem to support the hypothesis that permanent income is not likely to have sizeable effects on current BMI in the short run.

Theoretically, this lack of association between lifetime income and BMI in the short run may reflect that consumption and physical activity behaviors require time to react to income changes. However, it is also possible that we are not able to detect a statistically significant relationship between permanent income and current BMI due to the introduction of nonclassical measurement error when controling for last year's BMI. Furthermore, the reducedform estimate of the BMI-income relationship is likely to obfuscate the implicit relationships between consumption of food, physical activity and income. Unfortunately, the information available in our dataset does not allow us to distinguish among these alternatives.

Future research may shed more light on the explanations behind the apparent absence of a relationship between current BMI and lifetime income in the short run. It would be interesting to compare the estimates from the reduced-form version of the BMI's dynamic equation with the estimates from the entire structural model composed of the three equations: 
BMI's dynamic equation, food consumption demand, and physical activity demand. This obviously requires having data on consumption, physical activity, income and BMI.

\section{APPENDIX}

\section{A. Misclassification in the Obesity Indicator}

Misclassification in the obesity indicator results from the fact that self-reported anthropometric variables contain measurement error. With a continuous dependent variable, classical measurement error only affects the precision of the estimates. However, with discrete dependent variables (like being obese or not), even if the measurement error is classical, our estimates not only are less precise, but also biased (Hausman, 2001). The consequences of measurement error are exacerbated by the fact that this is not classical, since heavier persons are more likely to underreport their weight (see for example, Boström and Diderichsen, 1997). As Sanz-de-Galdeano (2005) recognizes, if an alternative dataset with objectively measured anthropometric indicators were available, she could correct for measurement error in self-reported BMI, like in Cawley (2000). However, using a continuous variable (BMI) as our dependent variable allows us to deal with the bias that would be caused by using a discrete

indicator (obesity), provided that the measurement error is classical. Even if measurement error is not classical, the bias due to measurement error can be somewhat attenuated when using a continuous variable (Boström and Diderichsen, 1997). Moreover, the obesity misclassification problem may be potentially aggravated because she uses household income quintiles, which are likely to suffer from misclassification error too.

\section{B. Demographic Covariates in the Augmented Specification}

Education level is defined by three dummies, a dummy for third level completed (ISCED 5-7), a dummy for second level completed (ISCED 3), and a dummy for less than second level completed (ISCED 0-2); marital status is defined as a dummy which takes value 1 if married, and 0 otherwise; smoking behavior is defined by a dummy which takes value 1 if the individual smokes daily, and 0 otherwise. The augmented regression also includes controls for the number of children between 13 and 15, and the number of children below 12 . 


\section{References}

[1] Behr, A., Bellgardt, E., and U. Rendtel (2005). Extent and Determinants of Panel Attrition in the ECHP. European Sociological Review 21:489-512.

[2] Boström, G., and F. Diderichsen (1997). Socioeconomic Differentials in Misclassification of Height, Weight and Body Mass Index Based on Questionnaire Data. International Journal of Epidemiology 26:860-866.

[3] Cawley, J. (2000). Body Weight and Women's Labor Market Outcomes. National Bureau of Economic Research, Working Paper No. 7841.

[4] Cawley, J., and R. Burkhauser (2006). Beyond BMI: The Value of More Accurate Measures of Fatness and Obesity in Social Science Research. National Bureau of Economic Research, Working Paper No. 12291.

[5] Chou, S., Grossman, M., and H. Saffer (2004). An economic analysis of adult obesity: results from the Behavioral Risk Factor Surveillance System. Journal of Health Economics $23: 565-587$.

[6] Cutler D., Glaeser E., and J. Shapiro (2003). Why Have Americans Become More Obese? Journal of Economic Perspectives 17:93-118.

[7] Finkelstein, E., Ruhm, C., and K. Kosa (2005). Economic Causes and Consequences of Obesity. Annual Review of Public Health 26:239-257.

[8] Garcia J., and C. Quintana-Domeque (2006). Obesity, Employment and Wages in Europe. In Bolin K., and J. Cawley, eds., Advances in Health Economics and Health Services Research 17. The Economics of Obesity, Amsterdam: Elsevier. In press.

[9] Griliches Z., and V. Ringstad (1970). Error-in-the-Variables Bias in Nonlinear Contexts. Econometrica 38:368-70.

[10] Hausman, J. (2001). Mismeasured Variables in Econometric Analysis: Problems from the Right and Problems from the Left. Journal of Economic Perspectives 15:57-67. 
[11] International Obesity Task Force (2002). Obesity in Europe: The case for action. International Obesity Task Force and European Association for the Study of Obesity.

[12] International Obesity Task Force (2003). Obesity in Europe 2: Waiting for a green light for health? Europe at the crossroads for diet and disease. International Obesity Task Force and European Association for the Study of Obesity.

[13] International Obesity Task Force (2005). EU Platform on Diet, Physical Activity and Health. International Obesity Task Force and European Association for the Study of Obesity.

[14] Jones A., Koolman X., and N. Rice (2006). Health-related non-response in the BHPS and ECHP: Using inverse probability weighted estimators in nonlinear models. Journal of the Royal Statistical Society Series A (Statistics in Society), 169.

[15] Lakdawalla D., and T. Philipson (2002). The Growth of Obesity and Technological Change: a Theoretical and Empirical Examination. National Bureau of Economic Research, Working Paper No. 8946.

[16] Lakdawalla D., and T. Philipson (2006). Labor Supply and Weight. Journal of Human Resources, forthcoming.

[17] Michaud P-C., and A. van Soest (2005). Obesity, Health and SocioEconomic Status: An International Comparison. Available at http://www.ifkcfs.de/papers/rtn0505_paper_Michaud_vanSoest.pdf [Last date of access: 31 August $2006]$

[18] OECD (2006). OECD Factbook 2006 - Economic, Environmental and Social Statistics. Available at http://www.sourceoecd.org/factbook [Last date of access: 31 August 2006]

[19] Peracchi, F. (2002). The European Community Household Panel: A review. Empirical Economics 27:63-90.

[20] Philipson T., and R. Posner (1999). The Long-Run Growth in Obesity as a Function of Technological Change. National Bureau of Economic Research, Working Paper No. 7423. 
[21] Philipson T. (2001). The World-Wide Growth in Obesity: an Economic Research Agenda. Health Economics 10:1-7.

[22] Sanz-de-Galdeano, A. (2005). The Obesity Epidemic in Europe. IZA Discussion Paper No. 1814.

[23] Sobal J., and A. Stunkard (1989). Socioeconomic Status and Obesity: A Review of the Literature. Psychological Bulletin 105:260-275.

[24] Thomas D., and E. Frankenberg (2002). The Measurement and Interpretation of Health in Social Surveys. In Murray C., Salomon J., Mathers C., and A. Lopez, eds., Summary Measures of Population Health, Geneva, World Health Organization.

[25] Thompson D., and A. Wolf (2001). The medical-care cost burden of obesity. Obesity Reviews 2:189-197.

[26] World Health Organization (2003). Diet, Nutrition, and the Prevention of Chronic Diseases. WHO Technical Report Series 916, Geneva.

[27] World Health Organization (2005). The challenge of obesity in the WHO European Region. Fact sheet EURO/13/05. 
Table - 1. BMI Distributions in 2001 by Country and Gender, age 25-54

Percentiles

\begin{tabular}{|c|c|c|c|c|c|c|c|}
\hline & Mean & 10 & 25 & 50 & 75 & 90 & $\mathbf{N}$ \\
\hline \multicolumn{8}{|l|}{ Men } \\
\hline Belgium & 25.08 & 20.37 & 22.15 & 24.62 & 27.76 & 30.30 & 1,330 \\
\hline Denmark & 25.13 & 21.13 & 22.72 & 24.70 & 26.88 & 29.54 & 1,254 \\
\hline Greece & 25.78 & 22.04 & 23.55 & 25.47 & 27.45 & 29.39 & 2,633 \\
\hline Ireland & 25.16 & 21.05 & 22.86 & 24.82 & 27.10 & 29.41 & 1,230 \\
\hline Italy & 24.79 & 20.99 & 22.53 & 24.38 & 26.59 & 29.00 & 4,382 \\
\hline Portugal & 25.34 & 21.55 & 22.95 & 25.01 & 27.17 & 29.41 & 3,288 \\
\hline Spain & 25.70 & 21.45 & 23.15 & 25.28 & 27.69 & 30.42 & 3,674 \\
\hline \multicolumn{8}{|l|}{ Women } \\
\hline Belgium & 23.44 & 19.15 & 20.57 & 22.49 & 25.25 & 29.07 & 1,476 \\
\hline Denmark & 24.13 & 19.62 & 21.26 & 23.14 & 26.35 & 29.64 & 1,265 \\
\hline Greece & 23.87 & 19.53 & 21.01 & 23.23 & 25.85 & 28.91 & 2,763 \\
\hline Ireland & 23.80 & 19.20 & 20.76 & 23.12 & 26.22 & 29.00 & 1,292 \\
\hline Italy & 22.77 & 18.75 & 20.20 & 22.06 & 24.56 & 27.55 & 4,483 \\
\hline Portugal & 24.37 & 19.82 & 21.45 & 23.44 & 26.44 & 30.08 & 3,355 \\
\hline Spain & 23.57 & 19.07 & 20.55 & 22.66 & 25.71 & 29.36 & 3,698 \\
\hline
\end{tabular}

Note: Observations have been weighted using the ECHP personal weights. 
Table - 2. Determinants of BMI for Men between 25-54 in 2001: OLS Estimates

Dependent Variable: BMI in 2001

\begin{tabular}{lcccccccc}
\hline & Belgium & Denmark & Greece & Ireland & Italy & Portugal & Spain \\
BMI in 2000 & $.967 * * *$ & $.934^{* * *}$ & $.815^{* * *}$ & $.748^{* * *}$ & $.900^{* * *}$ & $.933^{* * *}$ & $.826^{* * *}$ \\
& $(.019)$ & $(.025)$ & $(.025)$ & $(.034)$ & $(.012)$ & $(.017)$ & $(.033)$ \\
Income $1^{\text {st }}$ Tercile & -.036 & $.345^{* *}$ & .142 & -.251 & $.125^{*}$ & .179 & .327 \\
& $(.129)$ & $(.167)$ & $(.123)$ & $(.225)$ & $(.076)$ & $(.118)$ & $(.209)$ \\
Income $3^{\text {rd }}$ Tercile & .046 & .067 & -.221 & -.265 & -.026 & .176 & .277 \\
& $(.142)$ & $(.204)$ & $(.139)$ & $(.301)$ & $(.096)$ & $(.138)$ & $(.326)$ \\
& & & & & & & \\
\hline
\end{tabular}

Note: All regressions include a constant term and country dummies. Standard errors robust to heteroskedasticity are in parentheses. Observations have been weighted using the ECHP personal weights.

${ }^{*}$ p-value $<.1,{ }^{* *}$ p-value $<.05,{ }^{* * *}$ p-value $<.01$

Table - 3. Determinants of BMI for Women between 25-54 in 2001: OLS Estimates

Dependent Variable: BMI in 2001

\begin{tabular}{|c|c|c|c|c|c|c|c|}
\hline & Belgium & Denmark & Greece & Ireland & Italy & Portugal & Spain \\
\hline BMI in 2000 & $\begin{array}{c}.893 * * * \\
(.031)\end{array}$ & $\begin{array}{c}.941^{* * *} \\
(.023)\end{array}$ & $\begin{array}{c}.868 * * * \\
(.018)\end{array}$ & $\begin{array}{c}.871 * * * \\
(.034)\end{array}$ & $\begin{array}{c}.881 * * * \\
(.022)\end{array}$ & $\begin{array}{c}.970 * * * \\
(.017)\end{array}$ & $\begin{array}{c}.818 * * * \\
(.058)\end{array}$ \\
\hline Income $1^{\text {st }}$ Tercile & $\begin{array}{c}.183 \\
(.350)\end{array}$ & $\begin{array}{l}-.106 \\
(.216)\end{array}$ & $\begin{array}{c}.140 \\
(.157)\end{array}$ & $\begin{array}{c}.348 \\
(.288)\end{array}$ & $\begin{array}{c}.036 \\
(.106)\end{array}$ & $\begin{array}{c}.038 \\
(.120)\end{array}$ & $\begin{array}{c}.301 \\
(.248)\end{array}$ \\
\hline Income $3^{\text {rd }}$ Tercile & $\begin{array}{l}-.167 \\
(.137)\end{array}$ & $\begin{array}{l}-.130 \\
(.143)\end{array}$ & $\begin{array}{l}-.078 \\
(.150)\end{array}$ & $\begin{array}{l}-.132 \\
(.237)\end{array}$ & $\begin{array}{l}-.072 \\
(.087)\end{array}$ & $\begin{array}{c}.052 \\
(.137)\end{array}$ & $\begin{array}{l}-.089 \\
(.175)\end{array}$ \\
\hline
\end{tabular}

Note: See note Table - 2 . 
Table - 4. Determinants of BMI for Men between 25-54 in 2001: OLS Estimates with controls

Dependent Variable: BMI in 2001

\begin{tabular}{|c|c|c|c|c|c|c|c|}
\hline & Belgium & Denmark & Greece & Ireland & Italy & Portugal & Spain \\
\hline BMI in 2000 & $\begin{array}{c}.964 * * * \\
(.020)\end{array}$ & $\begin{array}{c}.934 * * * \\
(.027)\end{array}$ & $\begin{array}{c}.795 * * * \\
(.026)\end{array}$ & $\begin{array}{c}.735 * * * \\
(.034)\end{array}$ & $\begin{array}{c}.894 * * * \\
(.013)\end{array}$ & $\begin{array}{c}.918 * * * \\
(.017)\end{array}$ & $\begin{array}{c}.822 * * * \\
(.036)\end{array}$ \\
\hline Income $1^{\text {st }}$ Tercile & $\begin{array}{l}-.017 \\
(.139)\end{array}$ & $\begin{array}{l}.330 * * \\
(.165)\end{array}$ & $\begin{array}{c}.039 \\
(.122)\end{array}$ & $\begin{array}{l}-.373^{*} \\
(.219)\end{array}$ & $\begin{array}{c}.093 \\
(.079)\end{array}$ & $\begin{array}{c}.120 \\
(.115)\end{array}$ & $\begin{array}{c}.244 \\
(.218)\end{array}$ \\
\hline Income $3^{\text {rd }}$ Tercile & $\begin{array}{c}.100 \\
(.148)\end{array}$ & $\begin{array}{c}.045 \\
(.209)\end{array}$ & $\begin{array}{l}-.178 \\
(.141)\end{array}$ & $\begin{array}{l}-.131 \\
(.303)\end{array}$ & $\begin{array}{c}.015 \\
(.096)\end{array}$ & $\begin{array}{c}.129 \\
(.124)\end{array}$ & $\begin{array}{c}.307 \\
(.289)\end{array}$ \\
\hline \multicolumn{8}{|c|}{$\begin{array}{l}\text { Note: All regressions include a constant term and country dummies. Furthermore, individual } \\
\text { heterogeneity is somewhat accounted for using the following controls: age, two educational } \\
\text { dummies, a dummy of married, the number of children under } 13 \text { in the household, and the } \\
\text { number of children between } 14 \text { and } 15 \text { in the household. Standard errors robust to } \\
\text { heteroskedasticity are in parentheses. Observations have been weighted using the ECHP } \\
\text { personal weights. } \\
\text { p-value }<.1,{ }^{* *} \text { p-value }<.05,{ }^{* * *} \text { p-value }<.01\end{array}$} \\
\hline
\end{tabular}

Table - 5. Determinants of BMI for Women between 25-54 in 2001: OLS Estimates with controls

Dependent Variable: BMI in 2001

\begin{tabular}{lccccccc}
\hline & Belgium & Denmark & Greece & Ireland & Italy & Portugal & Spain \\
BMI in 2000 & $.888^{* * *}$ & $.948^{* * *}$ & $.857^{* * *}$ & $.868^{* * *}$ & $.865^{* * *}$ & $.958^{* * *}$ & $.771^{* * *}$ \\
& $(.030)$ & $(.022)$ & $(.021)$ & $(.034)$ & $(.024)$ & $(.019)$ & $(.064)$ \\
Income $1^{\text {st }}$ Tercile & .129 & -.028 & .232 & .465 & .006 & .056 & .243 \\
& $(.391)$ & $(.238)$ & $(.173)$ & $(.285)$ & $(.106)$ & $(.120)$ & $(.244)$ \\
Income $3^{\text {rd }}$ Tercile & -.114 & -.134 & -.054 & -.243 & -.026 & .034 & -.010 \\
& $(.146)$ & $(.149)$ & $(.144)$ & $(.238)$ & $(.089)$ & $(.153)$ & $(.159)$ \\
\hline
\end{tabular}

Note: See note Table -4 . 